\title{
Development of a Knowledge Management System Integrated with Local Communication Channels and Knowledge Management Initiatives for Kenyan Rural Farming Communities
}

\author{
N.M.A.E. Dewi Wirastuti ${ }^{1}$, Rose Luckin $^{2}$, Ray E. Sheriff ${ }^{1}$, Kevin Walker ${ }^{2}$, \\ Josh Underwood ${ }^{2}$, Lynne Dunckley ${ }^{3}$ \\ ${ }^{1}$ Mobile and Satellite Communications Research Centre, University of Bradford, \\ United Kingdom \\ ${ }^{2}$ London Knowledge Lab, University of London, United Kingdom \\ ${ }^{3}$ Thames Valley University, United Kingdom
}

\begin{abstract}
This paper presents an innovative application of wireless, mobile and ubiquitous technologies to support informal and collaborative learning in Kenyan rural farming communities. Such an approach is achieved by the development of a Knowledge Management System (KMS) integrated with existing local community communication channels, together with experimental Knowledge Management (KM) initiatives employing the VeSeL (Village e-Science for Life) distributed resource kits (DRKs). The initiatives support illiterate and semiliterate farming community groups, in learning new agriculture practices, and also enable the use of advanced digital technology to improve their agricultural practices and literacy levels. Results of a recent field trip to Kenya are presented and an application sketch is developed. The process of applying wireless and Internet technologies for the education of local farming communities, using irrigation and water management as the application, concludes the paper.
\end{abstract}

\section{Introduction}

Not all parts of the world are blessed with the latest in telecommunications services, and simply being able to place a call can be an achievement in itself. In parts of Africa, for example, where village communities represent a significant part of the population, a supporting telecommunications infrastructure is invariably nonexistent. In such parts of the world, the employment of mobile communications to alleviate the need for a fixed ground network infrastructure significantly speeds up the deployment of telecommunications facilities.

To achieve the vision of a global information society will require the widespread availability of Information and Communications Technologies (ICT) and the development of appropriate applications and media content. The widespread deployment of telecommunications services is a key to future economic prosperity, sustainable development and improvement in the quality of life of the 21 st century citizen. In this respect, bridging the ever-widening gap of the digital divide between developed and developing regions of the world is a fundamental component of establishing the global information society.

VeSeL (Village e-Science for Life), which began in September 2006, is a three-year project and is part of the Bridging the Global Digital Divide Network funded by the UK's Engineering and Physical Sciences Research Council [1]. The VeSeL project's objectives, which are focused on Kenyan rural farming communities, address both educational and technological issues in establishing the most urgent information and learning requirements and subsequently, designing and testing appropriate technologies to meet these needs. VeSeL aims to explore and develop participatory methods for novel sociotechnical solutions in rural communities with particular emphasis on overcoming educational barriers. This involves working with trainee teachers to enable them to explore ICT in novel ways to enhance ICT and basic skills, for example literacy and numeracy, in rural communities. Appropriate partnerships for long-term sustainability, for example with agricultural bureaus and local universities, will be formed, as will community networks with teachers and farmers.

In terms of technology, VeSeL intends to identify and develop the most appropriate technologies including: novel technologies for collecting, analyzing, archiving and visualizing information to support farmers to develop improved agricultural practices; innovative communication access facilities for sharing between isolated and dispersed rural communities; and radically 
different user interfaces for illiterate or semi-literate user groups.

Using DRKs, the interface and interaction approach of mobile, two-way information systems are designed. Mobile technologies are employed to bridge remote sensor networks and centralized ICT access points, with novel power solutions, usage scenarios, and device interfaces. The DRK includes equipment such as audio recorders, MP3/MP4 players and recorders, laptops, modems, handheld GPS units, digital cameras, solar powered charging and battery charging equipment; sensors and weather stations are self-contained interfaces of the KMS. The remainder of this paper is organised as follows: In Section 2, the background to the development of a Knowledge Management System (KMS) for African rural farming communities is presented. Section 3 then presents the existing local communication channels and constraints. Section 4 shows a web-based KMS for rural farming communities. In Section 5, KM initiatives for Kambu rural farming communities are proposed. Section 6 presents the explanation of KMS components, and finally, Section 7 provides some concluding remarks.

\section{Knowledge Management for Rural Farming Communities}

In order to be successful, Knowledge Management (KM) initiatives for Kenyan rural farming communities need to equally address both technological (i.e. Knowledge Management System (KMS)'s) and social dimensions (i.e. community culture) $[2,3]$. The degree of fit between the two KM dimensions should be reflected in the way communities interact with and the degree to which they accept the KMS [4], i.e. information systems designed to support individuals in performing KM-related agriculture activities. Accordingly, the aim of this paper is to develop a KMS model and dissemination scenario for Kenyan rural farming communities, integrated with existing local communication channels and introducing KM initiatives (involving advanced technology). These KM initiatives can be thought of as educational technology (or socio-technical) experiments.

Following analysis of data collected during visits to several communities in Kenya in November 2006, the VeSeL project decided to focus on two farming communities, one located in Kiangwaci and the other in Kambu. Key needs for these communities were identified to be improved information about funding for development, education about efficient water usage/water management, soil and fertilizers, pest control, crop management/suitable crops, improved access to weather and market information.
In order to support the delivery of these educational and informational needs, a 'system' is required that would use technology to provide local access to, collation and archiving of, and sharing of resources relevant to local needs. The system must also enable the community to publicise local needs, products, issues and news, and to communicate locally and globally. Thus, it enables collaboration with outside experts and other partners.

The following hardware and infrastructure requirements are proposed to develop a KMS model and dissemination scenario:

- Affordable efficient Internet access in Kambu and Kiangwaci;

- Caching of content from the KMS to the local content server;

- Interfacing of a local content server to data capture units, for example, from weather stations, sensors and records captured on handheld devices;

- Interfacing of local content server to existing local information delivery channels such as radio, mobile phones and public meetings;

- Interfacing of local content server to experimental delivery channels such as MP3/MP4 players;

- Innovative and inexpensive ways of charging varied battery powered portable devices (components of the resource kit mentioned above);

- $\quad$ The whole kit needs to be mobile to support working in dispersed communities. One option is for the entire kit to be carried on and possibly charged by a bicycle.

\section{Existing Local Communication Channels and Constraints}

Currently, within the Kenyan rural farming communities, radio and mobile phones are the most frequently used as a communications media; most people in the area listen to radio quite regularly, usually early in the morning before they set out for work or school, or in the evening. Kambu has its own radio station. Television is much less popular since most families do not own one or do not have electricity. In the town centre, bars, hotels and stores offer TV and at night time, some villagers make way to the centre to socialise. Radio Mangelete in Kambu is the only community radio in Kenya. It is owned by a number of community groups and is run by local volunteers.

At almost every place visited there were mobile phone signals, with Celtel providing the strongest coverage. Nevertheless, Safaricom appears to be the most popular network among the inhabitants. Some argue that this is due to the fact that Safaricom was the first to penetrate the town. However, the centre of the town experiences loss of 
signal whenever users are inside concrete buildings. With Celtel, although the signal strength is low within buildings, communication is still possible.

Almost every family has access to a mobile phone, either directly (owned) or indirectly (friends or relatives nearby). Cost of handset, charging and credit do not represent a barrier to accessing or acquiring one, although literacy is a barrier. Few houses have electricity to charge mobile phones. Therefore, most phones can be out of service for two to three days due to flat batteries. Recharging greatly depends also on the level of activity and income. Phones can be charged by traveling to the town centre to charge the phone weekly. In periods where farmers are not harvesting, and therefore not selling crops to earn income, charging or adding credit to a mobile can be delayed or ignored.

In terms of usage, farmers do not usually make telephone calls because of the expense and are not confident about using text messaging, which is viewed as time consuming. Normally, relatives and friends in the towns having salaried jobs will call the farmers. Those in the villages will not call then, unless it is an emergency, although there is adequate network reception to operate phones.

Local community-based organisations and farmer selfhelp groups use a variety of methods to disseminate information and educate communities including public meetings, theatre, murals and farmer field schools. Most families have children attending school as primary education is free in Kenya and education is generally regarded as important. Schools and school teachers have a significant role in the community.

\section{Web-Based Knowledge Management System for Rural Farming Communities}

The idea behind our KMS for Kenyan rural farming communities is to collect, store and disseminate knowledge with interfaces to existing local communication channels and experimental channels through the VeSeL DRK. Before the KMS scenarios and dissemination model are introduced, the Web-based KMS is first explained. The Web-based KMS is expected to deliver the following features through intermediaries (e.g. local NGOs, school, radio) to the farmers and to connect them to global communities of relevant expertise [5]:

- Provide online information and services about relevant agricultural practice;

- Support discussion and learning between local and remote communities around rural farming issues;

- $\quad$ Provide searchable information on agriculture;

- $\quad$ Provide access to expert advice and troubleshooting related to agricultural problems via the Internet;
- Educate communities in the use of the Internet to access important and useful information and services;

- Enable the communities to experiment with ways of using the Internet to support their lives.

The technical requirements of a Web-based KMS are as follows [6]:

- Web Server The hardware of the Web server is to be designed based on the traffic, network configuration, etc.

- $\quad$ Programming Language and Database

The programming language can be selected depending on the server support.

- KM Portal

One Web portal can be developed using any Internet hosting solutions and access can be restricted using login systems. Users with different levels of permission can access contributions/articles of different authors. This type of system helps in sharing best practices, experiments and innovations.

- Web-Based Discussion Board or Forum A virtual community can be created by using Webbased discussion boards. Different sections or areas can be created for discussions. Here, the discussions are available for all in the communities to view/post/reply to the topics. This is an ideal solution for communities located in different geographical areas but having common areas of interest such as rural farming communities.

- $\quad$ Blogs

Web logs ('blogs') are popular and companies have utilised this tool to create awareness and evolve opinions on different issues.

- Expert System

By encouraging communities to post their problems or difficulties to an expert system, they can save time and money in finding best solutions to their problems. This helps in creating innovation and a learning culture in the communities.

\section{A Scenario for Mobile, Ubiquitous and Collaborative Learning in Kambu}

In this paper, the dissemination scenarios will focus on Kambu farming communities, the homes of which are shown in Figure 1. The Kambu site is logistically more challenging because the community is spread out over a wide area and the farms are remote from the main roads even though Mtito Andei, the nearby town centre, is a stopping area on the main road between Nairobi and Mombassa. Accessing farms requires a means of transport such as 


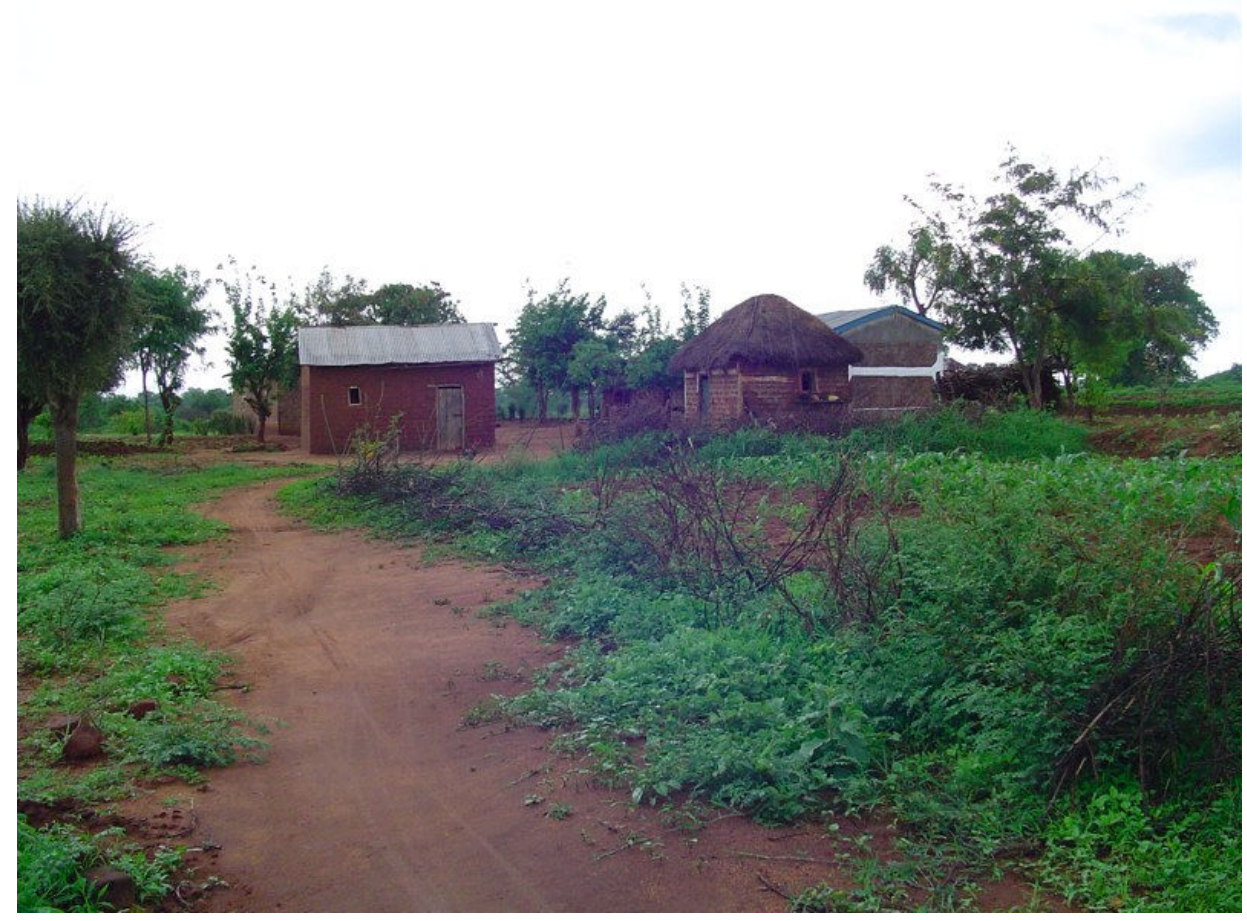

Figure 1. Homes in Kambu

motorbikes, bicycles or four-wheel drive vehicles. The level of education is also low, which has significance for language communication. The Kambu community is the needier because the lack of water makes crop production more challenging. On the other hand, Kiangwaci has a number of advantages, such as relative accessibility, plentiful water supply and rich soil, which is likely to mean ICT intervention produces results more rapidly, which will encourage the community to continue and persevere with the project. In addition, the community farms are much more compact.

The suggested use cases initially address the most urgent issues perceived by the investigators, which in Kambu are water management and irrigation. The KM initiatives and dissemination scenarios for Kambu communities are outlined as follows:

- $\quad$ Silanga School (in partnership with Mtito-Andei Development Initiative (MDI) and University of Nairobi (UoN)) start a $4 \mathrm{~K}$ club (4K=Kuungana, Kujenga, Kusaidia, Kenya; that is an agriculture club for students) with a demonstration shamba (Kiswahili for "field" or "garden") at a location near the existing water pump. The shamba is used to grow watermelons and to demonstrate efficient water management and good agricultural practice. Educational content relating to water management, good agricultural practice for arid lands and appropriate new crop opportunities is acquired and localised by VESEL through UoN agricultural colleagues, the Kenya Agriculture Research Institute (KARI) and other international partners. This content is stored on a remote, Webaccessible server (at University of Bradford, UK) and an international community is built around this content.

- Content is delivered to a local content server in $\mathrm{Kambu}$ - at the radio station - and disseminated via use in school/radio/public meetings. School activities utilising this content are designed and supported through appropriate use of the VeSeL DRK. Content can also be delivered as podcasts or requested from and delivered to mobile phones using a content server (similar to MobilED mediawiki system) [7].

- Pupils and staff are involved in recording the Shamba demonstration project and communicating it using activities and technology from the VeSeL DRK. These activities result in multimedia (audio/video/text) presentations. Use of the DRK is managed and facilitated by the teacher from Silanga School who has a successful agricultural practice. The DRK, which includes sensors for measuring local agricultural and weather conditions and provides remote access to global agricultural databases, is portable, so that it could be carried on a bicycle; the bicycle in turn may be used to charge some of the devices. 
- Progress on the demonstration shamba and experimental uses of ICT are communicated globally via the Silanga School, MDI and Mangelete Radio websites. The area of the MDI office is illustrated in Figure 2. Creation and management of these websites are facilitated through $\mathrm{VeSeL}$ with management gradually being taken on by local owners.

- $\quad$ Reports on project progress are also broadcast locally through Radio Mangelete. Staff and children at school are able to listen to broadcasts (and interactive radio) using wind-up radios (provided by VeSeL). These wind-up radios may also be used to charge low power items in the DRK, such as MP3 players. MP3 players with integrated radio can be used to record interactive education broadcasts, which can be archived and played back using low powered FM transmitters and the wind-up radios.

The school website is used to promote the project internationally and to attract global partners (e.g. UK Schools, AridLands, Gardens4Life); the school and other partner websites can also be used to promote specific projects developed by the local community/school and funding/donor requests.

An example of initial community publishing linked to school and related activities is presented in Figure 3. The school has the objective to communicate about itself and Kambu, in general. Each class takes it in turn to plan and produce a short report, news piece or 'study' resulting in a regular 'post' for the school website. Images, video and/or data are captured using borrowed devices and short 'multimedia' reports are planned 'on paper' and then authored on mobile phones. 'Reports' are delivered to local KMS (probably via short range communications). An ingestion system 'reads' reports and creates 'posts' on a local copy of the website/blog (which if necessary can be edited locally). An online mirror of the local KMS is updated (timing of this depends on resource centre connectivity options). The website is visible globally and may attract comments/questions - this can be stimulated by arranging school linking, etc. (comments to an online site need to be mirrored on the local copy).

Figure 4 presents an example of initial water education and related activities. Researchers identify, translate and repurpose educational material on water harvesting/drought resistant crops/irrigation/water usage. Material is collated and made available online and at the MDI resource centre local server. Information and knowledge is disseminated via local radio, resource centre screenings, posters, etc. Local 'water' action/projects are reported online via 'community blogs' along with requests for expertise, funding, questions, etc. The MDI copy of 'community blogs' is mirrored to an online site and read globally; comments and advice are posted by outsiders and then fed back to the local community.

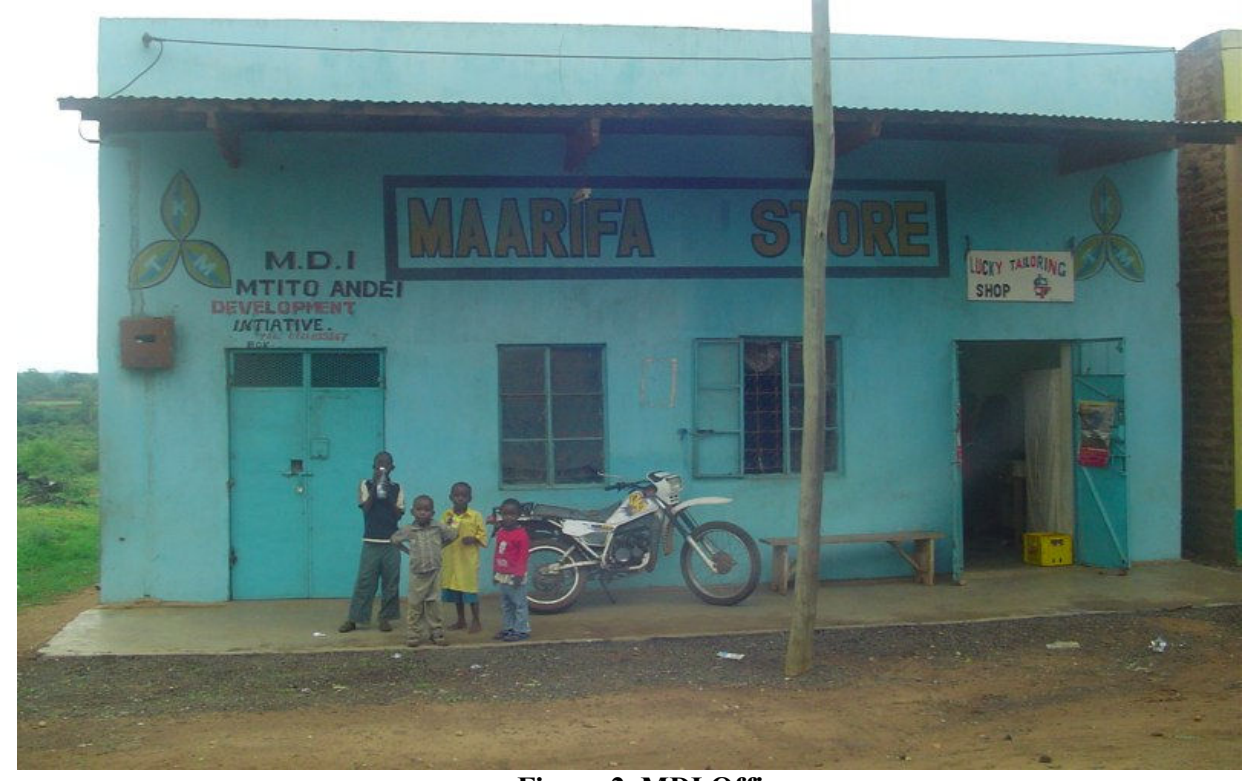

Figure 2. MDI Office 


\section{Knowledge Management System Components}

According to the scenarios and sketches, KMS components are shown in Figure 5. There are five components of the KMS: content, technologies, VeSeL DRK (output), resources (input) and technical specification. Content is a collection of data, information and knowledge that is needed by the Kambu rural farming community: funding for development, water usage/water management, soil and fertilizers, education, pest control, crop management/suitable crops, weather, and market information. It is planned to explore appropriate technologies that are suitable to farming community needs. Social networking, personal learning and mobile device interfaces to Web services are preferred. The KMS will interface with the VeSeL DRK, either directly to the community or via a mediator (student, public meeting, teacher, theatre).

A dissemination scenario of the KMS to the community can be seen in Figure 6. A KMS resource (or input) will be reliable information from the locality (e.g. soil sensors, weather station) and beyond (e.g. Internet, radio), local knowledge and expertise, such as that possessed by MDI, other community members and tools such as mobile phones, MP3/MP4 players and recorders, word processing and email. The technical specification for KMS is divided into two groups: hardware and software. Drupal and MobilED are candidate platform for KMS development, which could include mobile device interfaces to web services, for example, Facebook, and a combination of some functions available in social networking/software such as Flickr, MySpace, YouTube, according to community's interest and behaviors.

\section{Conclusions}

There are now a number of technological solutions that are bringing ever closer the realisation of the information society in many parts of the world. However, many parts of the world are devoid of communication facilities and there is a real danger that the digital divide will eventually be too great to bridge. Key to addressing the digital divide are affordable wireless communications devices and the Internet. Wireless communications has an important part to play in many parts of the world where a fixed network infrastructure is not available. Similarly, the Internet provides the opportunity to disseminate activities, to gain access to information and to communicate with groups of a similar nature on a global scale. VeSeL aims to combine these technologies to provide a basis for educating rural African farming communities by focusing on two villages in Kenya.

Work has already commenced on developing an integrated KMS, which will be used to provide education in water management and agricultural practice. For future developments, the school and community will use the KMS and DRKs in other exploratory educational activities designed by $\mathrm{VeSeL}$ (for example, to map and communicate the location of important local resources wells, etc.). Gradually the school and community will become involved in designing their own activities using the DRK and facilitated by local and remote VeSeL partners (e.g. a local farmer offers to plant and look after Jatropha for people in the developed world wanting to sponsor 'trees' to offset $\mathrm{CO}_{2}$ production; a website is designed to promote the business, people can sponsor a tree through Paypal or directly by international text messages; payment is delivered to the farmer through their mobile phone; the sponsor receives an MMS of their tree being planted or sees it on the online photo blog, tree location can be seen on Google Earth, perhaps also the sponsor can pay to see how the tree is growing again in the future, farmer pays $\mathrm{VeSeL}$ facilitator for service provided in setting up and recording tree planting).

The first scenario of DRKs implementation started in January 2008 where laptops, digital camera and audio recorders were delivered to Kenya. The laptops are supplemented with GPRS modems and a data plan, and this will provide a first fixed Internet connectivity solution for the community. An interactive scenario for school and community has designed. This will be a good starting point for the community to be familiar with the activities before they get involved in KMS activity. We expect to report initial results about the introduction and use of DRKs at the WMUTE conference. 


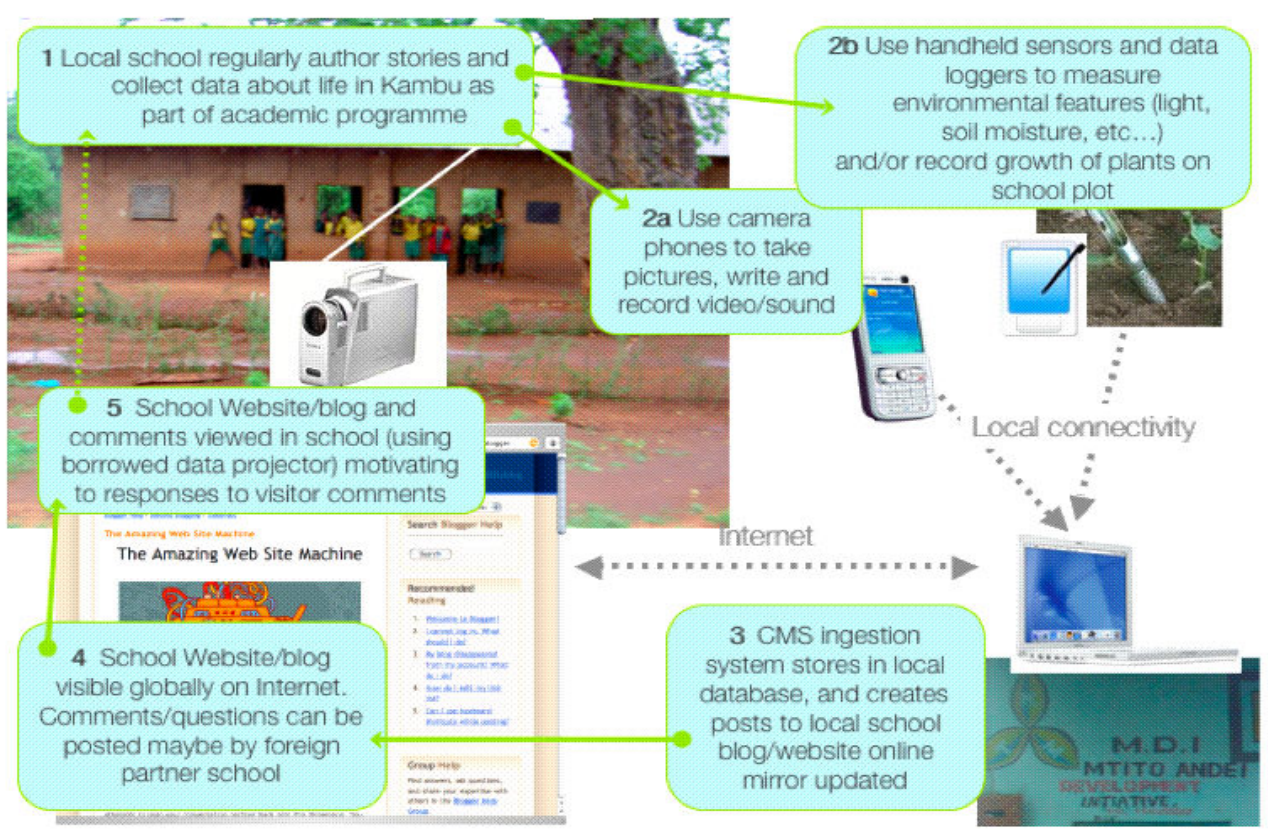

Figure 3. Initial Community Publishing Linked to School Sketch

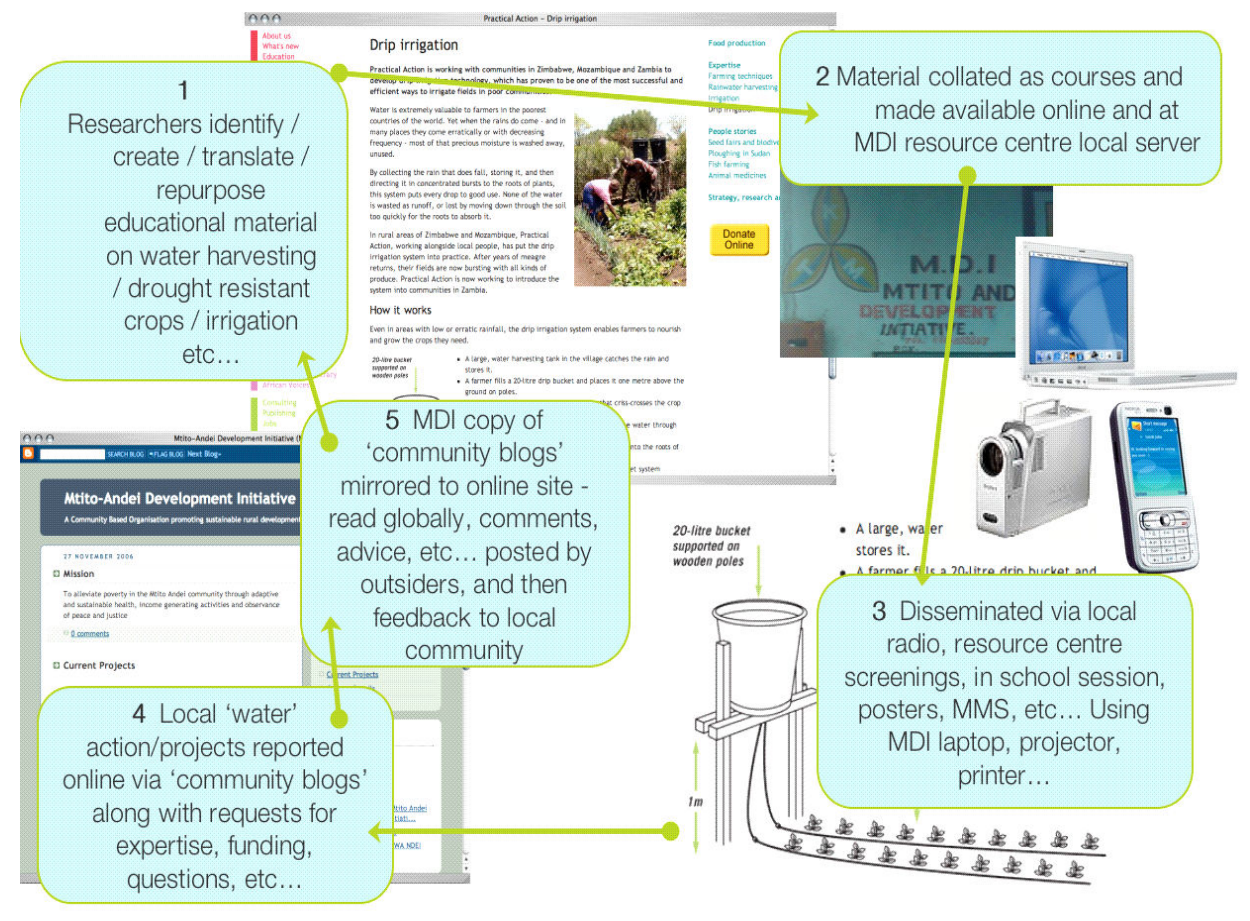

Figure 4. Initial Water Education Sketch 


\section{References}

[1] VeSeL: Village e-Science for Life. [Online]. Available: http://www.veselproject.net/index.php?q=about, Date of Access: $3^{\text {rd }}$ October 2007.

[2] Alavi, Maryam, and Leidner, D. Review: Knowledge Management and Knowledge Management Systems: Conceptual Foundations and Research Issues. MIS Quarterly, 25(1), March, 2001, 107-136.

[3] Marwick, A. D., Knowledge management technology. IBM Systems Journal, 40(4), 2001, 814-840.

[4] Bals, C., Smolnik, S., and Riempp, G. Assessing User Acceptance of a Knowledge Management System in a Global Bank: Process Analysis and Concept Development. In $40^{\text {th }}$ Annual Hawaii International Conference on System Sciences (HICSS 2007), 2007, 203c.
[5] Deraman, A. B., and Bahar, A. K. S. Bringing the Farming Community into the Internet: A Case Study. Informing Science, 3(4), 2000, 207-214.

[6] allkm. Web-based Knowledge Management. [Online]. Available:

http://allkm.bannersnbuttons.com $/ \mathrm{km}$ system/web based kno wledge management.php, Date of Acces: $3^{\text {rd }}$ October 2007.

[7] MobilED. MobilED Initiative. [Online]. Available: http://mobiled.uiah.fi/, Date of Access: $3^{\text {rd }}$ October 2007.

\section{Acknowledgements}

The VeSeL project is part of the Bridging the Global Digital Divide Network and funded by the UK's Engineering and Physical Sciences Research Council (EPSRC).

The VeSeL project is performed by London Knowledge Lab, Imperial College London, Thames Valley University, University of Bradford, University of Nairobi and University of Leeds.

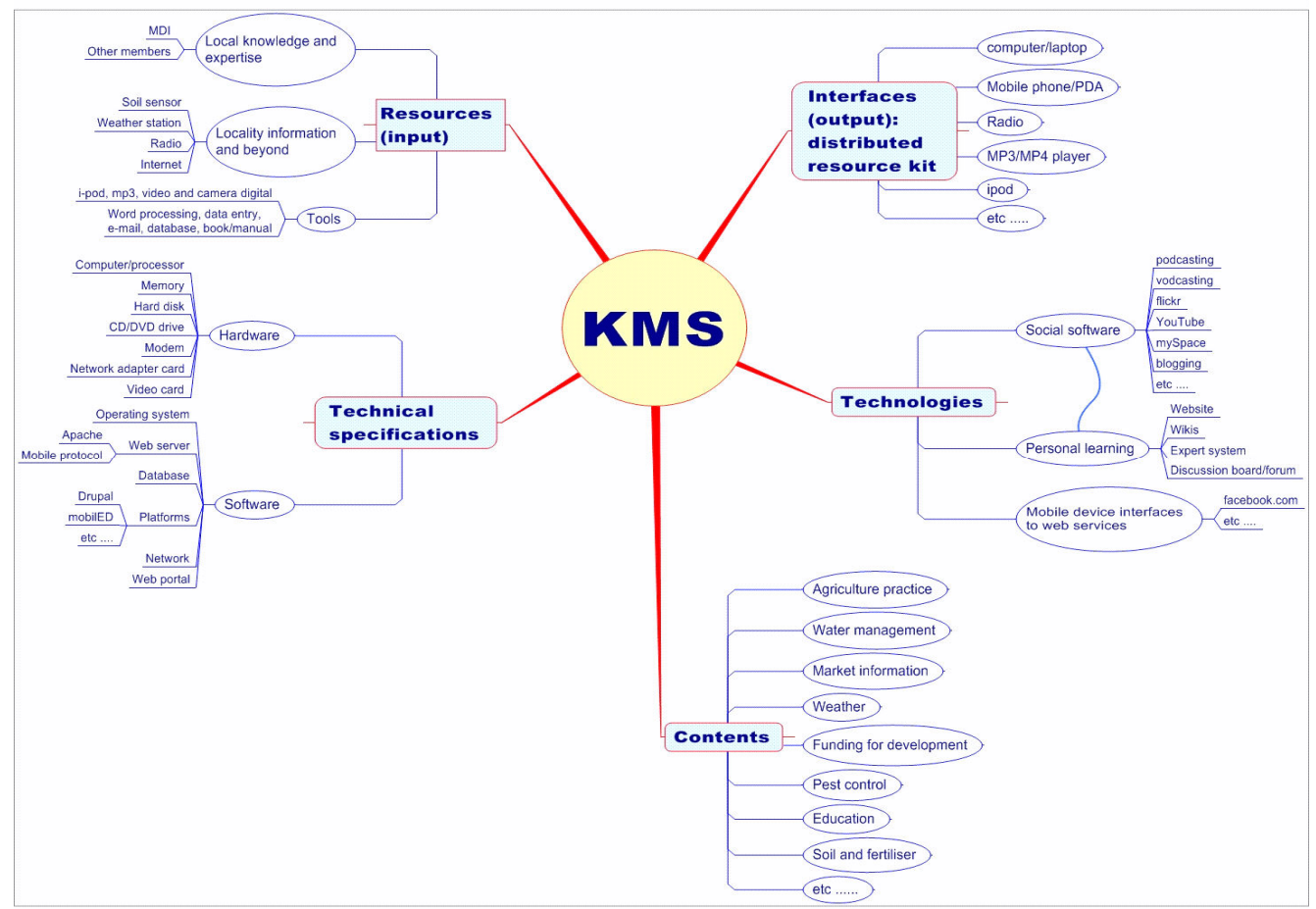

Figure 5. KMS Components

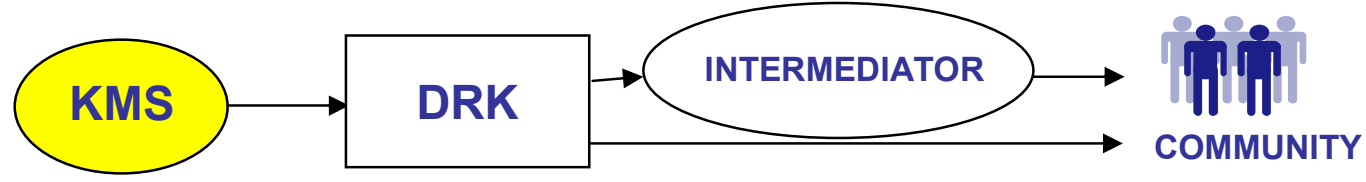

Figure 6. Knowledge Dissemination Scenarios with Interface to DRK 